(c) American Dairy Science Association, 2005.

\title{
Prevalence of Salmonella enterica in Bulk Tank Milk from US Dairies as Determined by Polymerase Chain Reaction*
}

\author{
J. S. Karns, ${ }^{1}$ J. S. Van Kessel, ${ }^{1}$ B. J. McCluskey, ${ }^{2}$ and M. L. Perdue ${ }^{1}$ \\ ${ }^{1}$ Environmental Microbial Safety Laboratory, USDA-ARS, Beltsville, MD 20705 \\ ${ }^{2}$ USDA-APHIS-VS-CEAH, Fort Collins, CO 80526
}

\begin{abstract}
Samples of bulk tank milk from dairies across the United States, taken as part of the National Animal Health Monitoring System Dairy 2002 survey, were analyzed for the presence of Salmonella enterica using a commercially available real-time polymerase chain reaction (PCR) kit. Samples from 854 farms in 21 states were collected and enriched in tetrathionate broth to amplify any salmonellae present, and DNA was isolated from the resulting biomass. One hundred one samples (11.8\%) were shown to contain Salmonella enterica using the real-time PCR assay, whereas conventional culture techniques detected the pathogen in only $22(2.6 \%)$ of the samples. A conventional PCR assay targeting a different gene from Salmonella enterica confirmed the presence of the organism in 94 of the real-time PCRpositive samples. Thus, assay of milk samples by realtime PCR indicates that the prevalence of Salmonella enterica in US bulk tank milk is substantially higher than previously reported.

(Key words: National Animal Health Monitoring System Dairy 2002 survey, real-time polymerase chain reaction, Salmonella enterica)
\end{abstract}

Abbreviation key: NAHMS = National Animal Health Monitoring System, RAPID = Ruggedized Advanced Pathogen Identification Device.

\section{INTRODUCTION}

Salmonellosis, a gastrointestinal infection caused by nontyphoid Salmonella enterica, affects an estimated 2 to 4 million people annually in the United States and is believed to be the second most common cause of bacterial foodborne illness in the country (Mead et al.,

\footnotetext{
Received December 29, 2004.

Accepted June 3, 2005.

Corresponding author: Jeffrey S. Karns; e-mail: karnsj@ba.ars. usda.gov.

*Mention of a trade name, proprietary product, or specific equipment does not constitute a guarantee or warranty by the USDA, and does not imply its approval to the exclusion of other products that may be suitable.
}

1999). Buzby and Roberts (1996) estimated Salmonella to be the most costly of 7 foodborne pathogens they examined, estimating the annual cost to the economy of the United States to be between $\$ 0.9$ to 12.2 billion. Salmonellae are rod-shaped, motile, gram-negative bacteria that infect many animals (cattle, poultry, swine), sometimes causing disease but often causing no overt symptoms. Because of this zoonotic nature, foods of animal origin are frequently associated with the spread of salmonellosis. Raw (unpasteurized) milk or products produced from raw milk have been implicated in outbreaks of salmonellosis in the United States and other industrialized countries (El-Gazzar and Marth, 1992; Cody et al., 1999; De Buyser et al., 2001; Centers for Disease Control and Prevention, 2003; Haeghebaert et al., 2003; Mazurek et al., 2004). Symptoms of salmonellosis in humans include diarrhea, abdominal cramps, and fever, all of which typically disappear within 1 wk. As with many illnesses, the young, elderly, and the immunocompromised have the most difficulty recovering from salmonellosis.

Salmonella contamination of bulk milk most likely occurs through fecal contamination, and mitigation through improved hygiene practices may be possible. However, testing for this organism is not routine. Bacteriological analysis of raw milk is typically limited to tests for bacterial groups (i.e., standard plate count and coliform count) or for specific mastitis-causing bacteria (i.e., Staphylococcus aureus and Streptococcus agalactiae) (Jayarao et al., 2001). However, it may also be useful to regularly monitor bulk tank milk for individual zoonotic pathogens. Traditional culture methods are usually time-consuming and labor intensive but improvements in DNA-based detection techniques may make screening of raw milk for a suite of organisms feasible.

Previously we reported on a real-time PCR method for the detection of Salmonella in raw milk (Van Kessel et al., 2003). Using 200 raw milk samples, 22 samples were identified as Salmonella-positive via traditional culture techniques but 54 samples were Salmonellapositive based on the real-time PCR assay. Therefore, it appeared that the real-time PCR method was more sensitive as well as faster than traditional culture tech- 
Table 1. Regions, states, and number of samples from each region used in the study.

\begin{tabular}{lll}
\hline Region & States & $\begin{array}{l}\text { No. of } \\
\text { samples }^{1}\end{array}$ \\
\hline West & CA, CO, ID, NM, TX, WA & $175(174)$ \\
Midwest & IL, IN, IA, MI, MN, MO, OH, WI & $361(361)$ \\
Northeast & NY, PA, VT & $257(251)$ \\
Southeast & FL, KY, TN, VA & $61(61)$ \\
\hline
\end{tabular}

${ }^{1}$ Numbers in parentheses indicate subset of the total samples from each region available for PCR analysis.

niques for the detection of Salmonella. The samples used in that study were a nonrandomly selected subset of bulk milk samples from the National Animal Health Monitoring System (NAHMS) Dairy 2002 survey. In this study, we report the results of a complete analysis of the bulk tank milk samples from the NAHMS Dairy 2002 survey using real-time PCR.

\section{MATERIALS AND METHODS}

The milk samples used in this study were collected during the NAHMS Dairy 2002 survey. The states, the breakdown into regions for this study, and the number of samples from each region are shown in Table 1. The methods for the collection, shipping, and analysis of bulk tank milk samples were described previously (Van Kessel et al., 2004). For enrichment of Salmonella, 5 to $10 \mathrm{~mL}$ of milk was added to $95 \mathrm{~mL}$ of tetrathionate broth. The variation in volume was due to variation in available sample volume. Enrichment bottles were incubated at $37^{\circ} \mathrm{C}$ for $24 \mathrm{~h}$ and then the broth was streaked $(10 \mu \mathrm{L})$ onto XLT4 agar (XLT4 agar base with XLT4 supplement; BD Diagnostics, Sparks, MD). Plates were incubated at $37^{\circ} \mathrm{C}$ and examined at 24 and $48 \mathrm{~h}$ for the presence of black colonies. In addition, 2 $\mathrm{mL}$ of the tetrathionate enrichment was centrifuged $(13,000 \times g, 2 \mathrm{~min})$, the supernatant removed, and the resulting pelleted material was suspended in $0.5 \mathrm{~mL}$ of a 1:1 mixture of the $2 \times$ freezing medium described by Schleif and Wensink (1981) and Lennox broth (Gibco Laboratories, Long Island, NY), and frozen at $-80^{\circ} \mathrm{C}$. To reculture a sample, the frozen material was thawed and mixed, and $0.1 \mathrm{~mL}$ was removed and spread evenly onto an XLT4 plate. The plates were incubated and scored as described above.

Isolated, presumptive Salmonella colonies were transferred from XLT4 plates onto XLT4, brilliant green agar, and Lennox broth plus $1.5 \%$ agar (L-agar) using sterile toothpicks. Colonies that exhibited the Salmonella phenotypes (black on XLT4 and pink on brilliant green agar) were preserved for future analysis. Colony biomass was transferred from the L-agar plates to a vial containing a 1:1 mixture of Lennox broth and
$2 \times$ freezing medium for cells (Schleif and Wensink, 1981), and the isolates were stored at $-80^{\circ} \mathrm{C}$. The Lagar slants were inoculated and, after incubation at $37^{\circ} \mathrm{C}$ for $24 \mathrm{~h}$, sent to the National Veterinary Services Laboratories in Ames, IA, for serotyping.

For PCR analysis, enriched samples $(1.5 \mathrm{~mL})$ were centrifuged $(13,000 \times g)$ in microcentrifuge tubes, the supernatants were discarded, and the pellets were stored at $-20^{\circ} \mathrm{C}$. The DNA was extracted from bacterial pellets using $200 \mu \mathrm{L}$ of InstaGene Matrix (Bio-Rad Laboratories, Hercules, CA) following the manufacturer's directions. The DNA preparations were stored at $-20^{\circ} \mathrm{C}$ and were analyzed for the presence or absence of Salmonella via real-time PCR later.

Real-time PCR was carried out using the Ruggedized Advanced Pathogen Identification Device (RAPID; Idaho Technology Inc., Salt Lake City, UT). Premixed, freeze-dried PCR reagents that target the $s p a \mathrm{Q}$ gene on the chromosome of Salmonella (RAPID systemSalmonella detection kit, Idaho Technology Inc.) were used according to the manufacturer's directions using $2 \mu \mathrm{L}$ of sample. Preincubation was at $94^{\circ} \mathrm{C}$ for $60 \mathrm{~s}$. Forty-five PCR cycles were run under the following conditions: $95^{\circ} \mathrm{C}$ for $0 \mathrm{~s}$ (the cuvettes are heated to $95^{\circ} \mathrm{C}$ but not held there), followed by $60^{\circ} \mathrm{C}$ for $20 \mathrm{~s}$ with a temperature transition rate of $20^{\circ} \mathrm{C} / \mathrm{s}$. Other variable parameters included: channel 2 , gain 8 , and mode 1 .

The RAPID system, in conjunction with the Salmonella detection kit, has the capability of running melting point curves on the PCR reaction products. Melting curves were run on all samples that were identified as Salmonella-positive by the RAPID software. The initial temperature was $94^{\circ} \mathrm{C}$ for $1 \mathrm{~min}$; the temperature was reduced to $50^{\circ} \mathrm{C}$, and then increased from 50 to $94^{\circ} \mathrm{C}$ at a rate of $0.2^{\circ} \mathrm{C} / \mathrm{s}$. The fluorescence in the sample was read at each stage of the temperature gradient and a first derivative plot of fluorescence vs. temperature was used to determine the melting point of any PCR products present. The software supplied by the manufacturer provides a score for each reaction based upon the degree that the maximum level of fluorescence recorded during the PCR run differs from the baseline calculated in the early stages of the run. Thus, the score depends upon the magnitude of fluorescent signal generated and the quality of the baseline. The higher the score, the more the maximum fluorescent signal varied from the baseline. For samples with a very low PCR score, a subjective analysis of the melting curve and the realtime PCR amplification curve was used to decide if a sample was finally considered Salmonella-positive or Salmonella-negative (Van Kessel et al., 2003). Logistic regression analysis of the relationship between realtime PCR signal and the likelihood of obtaining a posi- 
tive culture was done using the PROC PROBIT procedure in SAS 9.1 (SAS Inst. Inc., Cary, NC).

Samples that gave a positive result in the real-time assay were subjected to 2 rounds of conventional PCR using primer set 139-141 targeting the invA gene as described by Rahn et al. (1992) and shown by Malorny et al. (2003) to detect a wide range of salmonellae. The conditions for the first round of PCR were those described by Malorny et al. (2003) except that $1 \mathrm{U}$ of Amplitaq Gold (Applied Biosystems, Foster City, CA) was used per $25-\mu \mathrm{L}$ reaction, a $10-\mathrm{min}$ incubation at $95^{\circ} \mathrm{C}$ was added to activate the enzyme at the beginning of the reaction, and the PCR was run for 40 cycles. A portion $(1$ to $3 \mu \mathrm{L})$ of the InstaGene preparation from the tetrathionate broth enrichments of raw milk samples was added to each reaction. For the second round of PCR, $5 \mu \mathrm{L}$ of first-round product was added to $20 \mu \mathrm{L}$ of fresh PCR mix to give the same final composition as the first-round reactions. Amplification was done on a Biometra Personal Cycler (Biometra, Göttingen, Germany). The PCR products were separated by electrophoresis on a $2 \%$ horizontal agarose gel in Tris-borate buffer as described by Maniatis et al. (1982). The gel contained $0.5 \mu \mathrm{g} / \mathrm{mL}$ ethidium bromide; bands were visualized on a UV transilluminator, and documented with a video camera. Detection of a band in the region of $284 \mathrm{bp}$ indicated the presence of Salmonella.

\section{RESULTS}

Analysis of 854 bulk tank milk samples from the NAHMS Dairy 2002 survey by real-time PCR using the RAPID system and commercially available kits indicated that $101(11.8 \%)$ of the samples contained some level of Salmonella contamination (Table 2). The range of scores obtained and the number of samples that fell within each range is shown in Table 2. Of the 101 PCRpositive samples, only 20 of the enrichments from which they were derived yielded cultures of Salmonella when they were originally plated. A subset of PCR-positive, culture-negative samples from all ranges of PCR scores including 2 from the $>500$ range, 23 from the 100 to 499 range, 10 from the 50 to 99 range, 16 from the 20 to 49 range, 1 from the $<20$ range, along with 3 PCRnegative samples, were recultured by plating $100 \mu \mathrm{L}$ of the preserved enrichment (representing $40 \times$ the original volume of enrichment that was plated) onto XLT4 agar plates. In 6 cases, this resampling of larger volumes of preserved material yielded viable cultures of Salmonella enterica (Table 2). As might be expected, the enrichments with the highest real-time PCR scores, indicating a higher quantity of Salmonella DNA in the reaction, were more likely to yield a culturable Salmonella enterica strain upon plating. Logistic regression
Table 2. Number of bulk tank milk samples $(\mathrm{n}=854$ total) scored as positive by real-time PCR on RAPID ${ }^{1}$ by intensity of signal.

\begin{tabular}{llll}
\hline & $\begin{array}{l}\text { No. of } \\
\text { milk } \\
\text { samples }\end{array}$ & $\begin{array}{l}\text { No. of } \\
\text { culture- } \\
\text { positive } \\
\text { samples }(\%)\end{array}$ & $\begin{array}{l}\text { No. confirmed } \\
\text { by invA } \\
\text { PCR }(\%)\end{array}$ \\
\hline$\geq 500$ & 14 & $14(100)^{2}$ & $14(100)$ \\
$100-499$ & 30 & $7(23)^{3}$ & $30(100)$ \\
$51-99$ & 23 & $1(4)$ & $23(100)$ \\
$21-50$ & 28 & $3(11)^{4}$ & $24(86)$ \\
$\leq 20$ & 6 & $1(16)$ & $3(50)$ \\
Total & 101 & $26(26)$ & $94(93)$ \\
\hline
\end{tabular}

${ }^{1}$ RAPID $=$ Ruggedized Advanced Pathogen Identification Device (Idaho Technology Inc., Salt Lake City, UT). RAPID score is an indication of the magnitude of the fluorescent signal relative to the baseline for a sample. The higher the score, the more the signal varied from baseline.

${ }^{2}$ Twelve of the 14 culture-positive samples were detected upon initial culture; 2 were positive upon reculture using larger volumes.

${ }^{3}$ Five of the 7 culture-positive samples were detected upon initial culture; 2 were positive upon reculture using larger volumes.

${ }^{4}$ One of the 3 culture-positive samples were detected upon initial culture; 2 were positive upon reculture using larger volumes.

analysis indicated that the impact of signal amplitude on the likelihood of obtaining a positive culture was highly significant $(P<0.0001)$.

To confirm the presence of Salmonella in the cultures that tested positive with the real-time PCR assay, a conventional PCR assay targeting a different gene on the chromosome of the organism was run. The gene targeted for PCR was invA, because it has been shown that primer set 139-141 described by Rahn et al. (1992) detected all types of salmonellae and showed no cross reactions with other organisms (Malorny et al., 2003). Using this assay, 94 of the 101 samples (93\%) called Salmonella-positive by the real-time PCR analysis were confirmed as containing Salmonella (Table 2). As might be expected, the confirmation rate was higher when the scores for the real-time assay were highest and decreased for samples with low real-time scores; all 7 of the unconfirmed samples are from the 2 lowest PCR score groups. At present, it is not known whether these unconfirmed samples represent false positive real-time PCR or false-negative conventional PCR samples because both methods require a substantial degree of subjective judgment when the contamination levels are low.

The prevalence of Salmonella in bulk tank milk from 4 regions of the United States (see Table 1) as determined by PCR is shown in Figure 1. The prevalence rate varies from $15.5 \%$ in the Western region to $4.9 \%$ in the Southeast region. The PCR data generally parallel the culture data (derived from Van Kessel et al., 2004, but corrected for the 6 additional samples from which Salmonella was isolated as part of this study), 


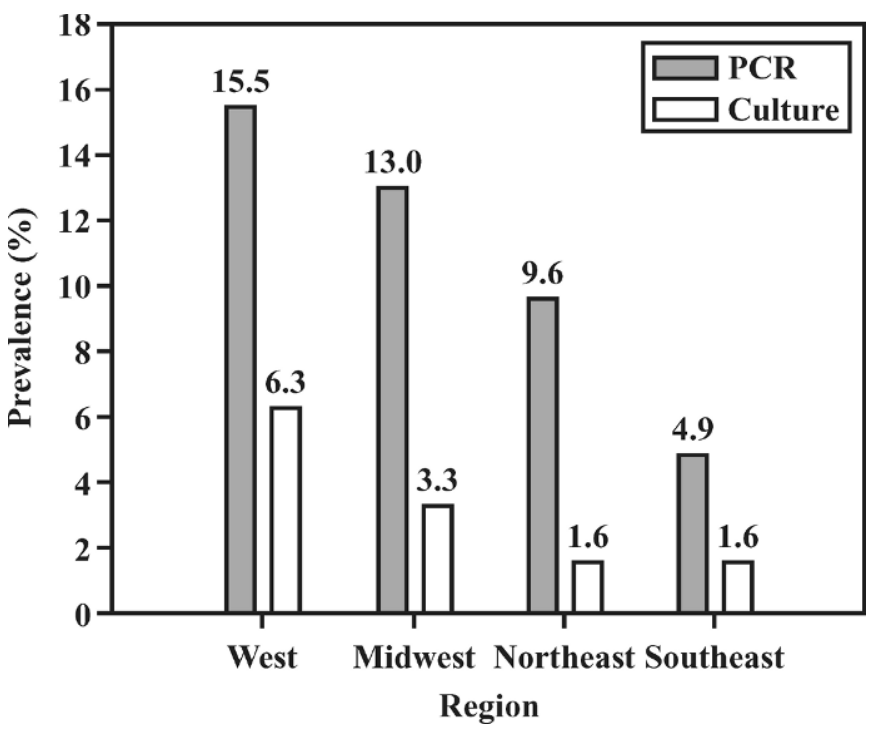

Figure 1. Regional distribution of Salmonella enterica in bulk tank milk samples from the National Animal Health Monitoring System Dairy 2002 survey as determined by PCR and culture. For PCR detection, the standard error of the mean (SEM) was less than $0.08 \%$ for all regions, and for detection by culture, SEM was less than $0.03 \%$.

which showed $6.3 \%$ of the Western region, $3.3 \%$ of the Midwest region, and $1.6 \%$ of the Eastern region samples contained Salmonella. However, PCR detected Salmonella contamination in $4.9 \%$ of the samples from the Southeast region whereas no Salmonella were originally cultured from any of the samples from this region (Van Kessel et al., 2003). Reculture resulted in the isolation of a viable culture of Salmonella from one PCRpositive sample from the Southeast region (1.6\%). The serotypes of Salmonella isolated were: Montevideo (9 samples); Cerro and Newport (4 samples each); Anatum, Meleagridis, Sal 44:Z36 and Muenster (2 samples each); Sal 9,12:nonmotile, Dublin, Kentucky, and Litchfield ( 1 sample each). The number of isolates totals 29 because 2 serotypes were isolated from one sample in one case.

\section{DISCUSSION}

A previous study suggested that a commercially available real-time PCR assay was effective for the detection of Salmonella in bulk tank milk samples when combined with enrichment in tetrathionate broth (Van Kessel et al., 2003). The PCR assay was able to detect the presence of Salmonella even in samples that did not yield positive cultures. When this assay was used to examine 854 bulk tank milk samples from the NAHMS Dairy 2002 survey, it indicated that 101 samples (11.8\%) were contaminated by Salmonella. Six of the original 861 samples were not examined by PCR; 5 arrived before the PCR protocol was developed and 1 sample was lost. A second PCR assay confirmed the presence of Salmonella in 94 of these real-time PCRpositive samples. Thus, it seems that the use of a realtime PCR assay after enrichment provides a rapid, accurate, and sensitive method for surveying the presence of Salmonella in bulk tank milk.

The PCR assay of bulk tank milk samples taken from the NAHMS Dairy 2002 survey suggests that substantially more milk samples contained detectable Salmonella than we previously reported in Van Kessel et al. (2004), in which culture techniques initially indicated that only $22(2.6 \%)$ were contaminated. In that study, 20 of the 861 milk samples cultured yielded viable Salmonella cultures upon enrichment in tetrathionate broth and plating, whereas 2 yielded viable Salmonella when directly plated on XLT-4 agar but not after the enrichment procedure. Based on the PCR results, viable Salmonella enterica cultures were obtained from 6 additional samples, increasing the total detected by culture and isolation of the organism to 28 out of 861 samples (3.3\%). There can be many reasons why Salmonella were not isolated from such a large number of PCRpositive samples. In all cases, the number of Salmonella in the original milk samples was very low as few yielded culture upon direct plating (Van Kessel et al., 2004). Bulk tank milk can contain many other organisms that may compete with Salmonella in the enrichment medium, keeping the total number of Salmonella lower than our detection limit on plates. Additionally, the presence of other organisms on the XLT4 selective agar plates may interfere with the production of $\mathrm{H}_{2} \mathrm{~S}$ by Salmonella; $\mathrm{H}_{2} \mathrm{~S}$ production is required for the formation of the black color in Salmonella colonies and hence, the visual identification of the organism. It is unlikely that the enrichment-PCR combination used here detected nonviable or nonculturable cells because the numbers in the original milk samples were very low and the milk was diluted 10 -fold or greater in the tetrathionate enrichment broth, which would have rendered any but the most grossly contaminated cultures undetectable by PCR.

Previous studies have shown a wide range of estimates for the prevalence of Salmonella in bulk tank milk. Steele et al. (1997) detected it in only $0.17 \%$ of bulk tank samples from Ontario, Canada. Murinda et al. (2002) found Salmonella spp. in $2.24 \%$ of milk samples from the bulk tanks of 30 Tennessee farms sampled repeatedly over a period from September to December. However, they observed that 7 farms that were part of the survey (25.3\%) had at least one sample positive for Salmonella during that period. Jayarao and Henning (2001) sampled 131 dairy farms in eastern South Da- 
kota and western Minnesota and detected Salmonella in $6.1 \%$ of the samples. Rohrbach et al. (1992) found Salmonella in $8.9 \%$ of 292 bulk tank milk samples taken from farms in eastern Tennessee. All these studies used enrichment followed by isolation on selective agars. Thus, Salmonella contamination of raw milk from dairies should not be considered a rare event. The study presented here differs from previous studies in that it is national in scope and it used a real-time PCR assay to detect Salmonella rather than isolation of the organism. The detection of Salmonella in $11.8 \%$ of the samples tested indicates that the degree of prevalence of the pathogen in raw milk in the United States is higher than originally believed.

Although contamination of dairy products currently accounts for a small percentage of foodborne illness in the United States, it is clear that raw milk consumption and the consumption of products made with raw milk present some risk. Although proper pasteurization minimizes these risks to the public, there is a small but growing group of people that consume unpasteurized milk or milk products, either for practical (e.g., farm families) or cultural (e.g., soft ethnic cheeses) reasons, or because of perceived health benefits (Cody et al., 1999; Villar et al., 1999; Anonymous, 2002). Although the levels of Salmonella in the milk samples tested here seemed to be very low and the infectious dose for this organism is high, the potential for this organism to grow in improperly stored raw milk and in products made from raw milk presents a public health risk, particularly to susceptible members of the population. Continuing surveys of milk will help estimate the true level of risk associated with these practices and may help to identify dairy management practices that minimize the contamination of bulk tank milk with zoonotic foodborne pathogens.

\section{ACKNOWLEDGMENTS}

We thank Thomas Jacobs, Jr., Sumit Dua, Sebastian Botero, and Kristie Hensel for technical assistance. We also thank Curtis Van Tassell for help with statistical analysis.

\section{REFERENCES}

Anonymous. 2002. Got milk? Washington Post, June 5, 2002.

Buzby, J. C., and T. Roberts. 1996. ERS updates US foodborne disease costs for seven pathogens. Food Rev. 19:20-25.

Centers for Disease Control and Prevention. 2003. Multistate outbreak of Salmonella serotype Typhimurium infections associated with drinking unpasteurized milk-Illinois, Indiana, Ohio, and Tennessee, 2002-2003. MMWR Morb. Mortal. Wkly. Rep. 52:613-615.
Cody, S. H., S. L. Abbott, A. A. Marfin, B. Schulz, P. Wagner, K. Robbins, J. C. Mohle-Boetani, and D. J. Vugia. 1999. Two outbreaks of multidrug-resistant Salmonella serotype Typhimurium DT104 infections linked to raw-milk cheese in Northern California. JAMA 281:1805-1810.

De Buyser, M.-L., B. Dufour, M. Maire, and V. Lafarge. 2001. Implication of milk and milk products in food-borne diseases in France and in different industrialized countries. Int. J. Food Microbiol. 67:1-17.

El-Gazzar, F., and E. H. Marth. 1992. Salmonellae, salmonellosis and dairy foods: A review. J. Dairy Sci. 75:2327-2343.

Haeghebaert, S., P. Sulem, L. Deroudille, E. Vanneroy-Adenot, O. Bagnis, P. Bouvet, F. Grimont, A. Brisabois, F. Le Querrec, C. Hervy, E. Espie, H. de Valk, and V. Vailant. 2003. Two outbreaks of Salmonella Enteritidis phage type 8 linked to the consumption of Cantal cheese made with raw milk, France, 2001. Eurosurveillance 8:151-156.

Jayarao, B. M., and D. R. Henning. 2001. Prevalence of foodborne pathogens in bulk tank milk. J. Dairy Sci. 84:2157-2162.

Jayarao, B. M., S. R. Pillai, D. R. Wolfgang, D. R. Griswold, and L. J. Hutchinson. 2001. Herd level information and bulk tank milk analysis: Tools for improving milk quality and herd udder health. Bovine Pract. 35:23-35.

Malorny, B., J. Hoorfar, C. Bunge, and R. Helmuth. 2003. Multicenter validation of the analytical accuracy of Salmonella PCR: Towards an international standard. Appl. Environ. Microbiol. 69: 290-296.

Maniatis, T., E. F. Fritsch, and J. Sambrook. 1982. Molecular Cloning-A Laboratory Manual. Cold Spring Harbor Laboratory, Cold Spring Harbor, NY.

Mazurek, J., E. Salehi, D. Propes, J. Holt, T. Bannerman, L. M. Nicholson, M. Bundensen, R. Duffy, and R. L. Moolenaar. 2004. A multistate outbreak of Salmonella enterica serotype Typhimurium infection linked to raw milk consumption-Ohio, 2003. J. Food Prot. 67:2165-2170.

Mead, P. S., L. Slutsker, V. Dietz, L. F. McCaig, J. S. Bresee, C. Shapiro, P. M. Griffin, and R. V. Tauxe. 1999. Food-related illness and death in the United States. Emerg. Infect. Dis. 5:607-625.

Murinda, S. E., L. T. Nguyen, S. J. Ivey, B. E. Gillespie, R. A. Almeida, F. A. Draughon, and S. P. Oliver. 2002 Molecular characterization of Salmonella spp. isolated from bulk tank milk and cull dairy cow fecal samples. J. Food Prot. 65:1100-1105.

Rahn, K., S. A. De Grandis, R. C. Clarke, S. A. McEwen, J. E. Galan, C. Ginocchio, R. Curtiss, III, and C. L. Gyles. 1992. Amplification of an invA gene sequence of Salmonella typhimurium by polymerase chain reaction as a specific method of detection of Salmonella. Mol. Cell. Probes 6:271-279.

Rohrbach, B. W., F. A. Draughon, P. M. Davidson, and S. P. Oliver. 1992. Prevalence of Listeria monocytogenes, Campylobacter jejuni, Yersinia enterocolitica, and Salmonella in bulk tank milk: Risk factors and risk of human exposure. J. Food Prot. 55:93-97.

Schleif, R. F., and P. C. Wensink. 1981. Practical Methods in Molecular Biology. Springer-Verlag, New York, NY.

Steele, M. L., W. B. McNab, C. Poppe, M. W. Griffiths, S. Chen, S. A. Degrandis, L. C. Fruhner, C. A. Larkin, J. A. Lunch, and J. A. Odumeru. 1997. Survey of Ontario bulk tank milk for foodborne pathogens. J. Food Prot. 60:1341-1346.

Van Kessel, J. S., J. S. Karns, L. Gorski, B. J. McCluskey, and M. L. Perdue. 2004. Prevalence of Salmonellae, Listeria monocytogenes, and fecal coliforms in bulk tank milk on US dairies. J. Dairy Sci. 87:2822-2830.

Van Kessel, J. S., J. S. Karns, and M. L. Perdue. 2003. Using a portable real-time PCR assay to detect Salmonella in raw milk. J. Food Prot. 66:1762-1767.

Villar, R. G., M. D. Macek, S. Simons, P. S. Hayes, M. J. Goldoft, J. H. Lewis, L. L. Rowan, D. Hursh, M. Patnode, and P. S. Mead. 1999. Investigation of multidrug-resistant Salmonella serotype Typhimurium DT104 infections linked to raw-milk cheese in Washington State. JAMA 281:1811-1816. 